\title{
Diurnal Alterations in Photosynthetic Pigments and Chlorophyll Fluorescence in Stay Green Wheat (Triticum aestivum L.) Genotypes under Heat Stress
}

\author{
Pramod Kumar* \\ Division of Plant Physiology, ICAR - Indian Agricultural Research Institute, \\ New Delhi 110 012, India \\ *Corresponding author
}

\begin{tabular}{|c|c|}
\hline \multicolumn{2}{|r|}{ A B S T R A C T } \\
\hline & \multirow{6}{*}{$\begin{array}{l}\text { A field study was conducted with an objective to assess diurnal variations in photosynthetic } \\
\text { pigments and chlorophyll fluorescence parameters in two stay green wheat genotypes viz. DL } 1266- \\
1 \text { and Arina } 166 \text { to gain insight into photoprotective regulation mediated by photosynthetic pigments } \\
\text { during grain filling under late sown heat stress condition. Heat stress was imposed by delaying } \\
\text { sowing date i.e. } 12^{\text {th }} \text { January. Diurnal alterations in temperature affected all the parameters } \\
\text { associated with photosynthetic pigments and chlorophyll fluorescence. Under heat stress condition, } \\
\text { PSII maximum efficiency (maximum quantum yield of PSII) }\left(\mathrm{F}_{\mathrm{v}} / \mathrm{F}_{\mathrm{m}}\right) \text { was utmost early in the } \\
\text { morning, afterwards it decreased up to midday and then it recovered in the late afternoon. } \\
\text { Photosynthetic pigments (chlorophylls and carotenoids) and the minimal fluorescence }\left(\mathrm{F}_{\mathrm{o}}\right) \text {, on the } \\
\text { contrary, were low in the early morning and highest during noon time. Over the course of the sunny } \\
\text { day, initial decrease and subsequent increases in both photochemical quenching (qP) and the } \\
\text { efficiency of excitation capture by open PSII centers }\left(\mathrm{F}_{\mathrm{v}}{ }^{\prime} / \mathrm{F}_{\mathrm{m}}{ }^{\prime}\right) \text { were observed. However, a contrary } \\
\text { trend was found in the changes of non-photochemical quenching (NPQ) that increased from morning } \\
\text { to afternoon and decreased thereafter which suggested the role of xanthophyll pigments in } \\
\text { photoprotection of photosynthetic machinery during midday hours. Genotypic diurnal varation in } \\
\text { photosynthetic pigments and chlorophyll fluorescence parameters particularly of total chlorophyll, } \\
\text { chla total carotenoids, ratio of Chl } \text { : Chl \& total carotenoids: total chlorophyll and non- } \\
\text { photochemical quenching (NPQ) were recorded sharper in DL } 1266-1 \text { as compared to Arina } 166 \text {. } \\
\text { Present study indicated that zeaxanthin cycle pigments based photoprotective mechanism is stronger } \\
\text { in DL } 1266-1 \text { as compared to Arina } 166 \text {. }\end{array}$} \\
\hline & \\
\hline $\begin{array}{l}\text { Carotenoids, } \\
\text { chlorophyll, } \\
\text { chlorophyll } \\
\text { fluorescence, diurnal } \\
\text { changes, stay green, } \\
\text { wheat }\end{array}$ & \\
\hline Artic & \\
\hline $\begin{array}{l}\text { Accept } \\
18 \text { July } \\
\text { Availa } \\
20 \mathrm{Au}\end{array}$ & \\
\hline & \\
\hline
\end{tabular}

\section{Introduction}

Wheat is one of the most widely cultivated cereal crop contributes nearly $30 \%$ of the world grain production and $50 \%$ of the world grain trade. It ranks first in terms of harvested area (223.67 million hectares in 2016) and is the second most produced crop with a global production of 735.3 million tons in 2016
(USDA, 2017) and often under abiotic stress. Today, the most alarming environmental concern in agriculture is the increase of global temperature. Wheat is very sensitive to heat stress. In India, because of delayed harvesting of rice and sugarcane crops, wheat is sown late, as a result wheat crop is damaged due to heat stress and that is an important factor for limiting wheat yields (Aslam et al., 1989). 
According to an estimate, global wheat production could reduce by $4.1 \%$ to $6.4 \%$ for each $1{ }^{\circ} \mathrm{C}$ increase in global temperature (Asseng et al., 2015).

High temperature during and after flowering, may cause premature senescence, resulting in poor grain quality and loss of yield (Zhang et al., 2013). In wheat, photosynthesis contributes $80-90 \%$ of assimilates for grain filling under optimum temperature conditions (Evans et al., 1975). Therefore, premature senescence and the rate of senescence may be important factors that influence yield potential under stress (Thomas and Howarth 2000). Chlorophyll tends to be photooxidized at high irradiance and carotenoids prevent chlorophyll photooxidation, therefore, relationship between chlorophyll and carotenoids may be used as a potential indicator of photooxidative damages caused by strong irradiation (Hendry and Price, 1993). Damage caused by photoinhibition may be evaluated by determining fluorescence. Chlorophyll (Chl) fluorescence quenching analysis has been proven as a non-invasive, powerful, and accurate method to evaluate the changes in function of photosystem II (PS II) under different environments (Schreiber et al., 1994). The photoinhibition takes place much frequently when strong irradiance is combined with high temperature, drought or other stresses in summer midday. Under heat stress plants particularly in noon often absorb more photons than its utilization for photosynthesis results photoinhibition. Furthermore, photoinhibition could result in photooxidative damage, pigment bleaching and even irreversible damage to the photosynthetic machinery (Ivanov et al., 2008). Xanthophyll cycle related thermal dissipation is the primary approach to prevent the photosynthetic apparatus from damaging by strong irradiance under natural conditions (Demmig-Adams and Adams 1992). Therefore, an attempt was made to elucidate the photosynthetic pigments and chlorophyll fluorescence diurnal variations in flag leaf of two stay green wheat genotypes during grain filling under heat stress to analyze their photoprotective role for heat tolerance.

\section{Materials and Methods}

\section{Plant material}

A field study was conducted at experimental farm, by selecting two stay green wheat genotypes viz. DL 1266-1 and Arina 166 from a set of 468 genotypes. Heat stress was imposed by delaying sowing date i.e. $12^{\text {th }}$ January and each observation was repeated thrice in third week of April during grain filling. All records were taken at 2 hour interval starting from 6.00 AM to 6.00 PM on sunny days when the temperature of midday crossed the $40{ }^{\circ} \mathrm{C}$. Field was watered at regular intervals depending upon the rainfall. All recommended agronomic practices were followed to cultivate the healthy crop.

\section{Chlorophyll fluorescence measurements}

Chlorophyll fluorescence measurements were performed using the Junior-PAM fluorometer (Heinz Walz, Germany). The leaf clips were attached on the flag leaves 20 minutes prior to the measurements to provide dark adaptation. After that, samples were illuminated to take light adapted records on chlorophyll fluorescence. The maximum efficiency of PSII photochemistry (Fv/Fm), efficiency of excitation capture by open PSII centers $\left(\mathrm{F}_{\mathrm{v}}{ }^{\prime} / \mathrm{F}_{\mathrm{m}}{ }^{\prime}\right)$, photochemical quenching (qp) and non-photochemical quenching (NPQ) were calculated according to Demmig-Adams et al., (1996).

\section{Photosynthetic pigments content}

Photosynthetic pigments were extracted from the same flag leaves which were used for the 
Chlorophyll fluorescence measurements. Chlorophyll and carotenoid contents were extracted following the method described by Hiscox and Israelstam 1979. The procedure for estimation of chlorophyll content in plants is based on the absorption of light by chlorophyll extracts prepared by incubating the leaf tissues in DMSO (dimethyl sulfoxide). DMSO makes plasmalemma permeable, by this means, causing the leaching of the pigments (Hiscox and Israelstam 1979). The absorbance of the known volume of solution containing known quantity of leaf tissue at two respective wavelengths (663 and 645) was determined for chlorophyll content and at 480 $\mathrm{nm}$ for total carotenoids contents. Chlorophyll 'a', chlorophyll ' $\mathrm{b}$ ' and total chlorophyll content were estimated using the formula given by Arnon, (1949) while carotenoids content was determined by following the formula given by Lichtenthaler and Welburn 1983. Twenty $\mathrm{mg}$ fresh leaf samples were added to the test tubes containing $4 \mathrm{ml}$ DMSO. Tubes were kept in dark for $4 \mathrm{~h}$ at 65 ${ }^{\circ} \mathrm{C}$. Then the samples were taken out cooled at room temperature and the absorbance was recorded at 663, 645 and $480 \mathrm{~nm}$ using DMSO as blank and was expressed as $\mathrm{mg} \mathrm{g}^{-1}$ dry wt.

Chlorophyll ' $\mathrm{a}$ ' $=\left(12.7 \times \mathrm{A}_{663}-2.69 \times \mathrm{A}_{645}\right) \mathrm{x}$ V/W x1000

Chlorophyll 'b' $=\left(22.9 \times \mathrm{A}_{645}-4.68 \times \mathrm{A}_{663}\right) \mathrm{x}$ V/W x1000

Total chlorophyll $=\left(20.2 \times \mathrm{A}_{645}+8.02 \times \mathrm{A}_{663}\right)$ $\mathrm{x}$ V/W x 1000

Total carotenoids $=\left(\mathrm{A}_{480}+\left(0.114 \times \mathrm{A}_{663}\right)-\right.$ $\left.\left(0.638-\mathrm{A}_{645}\right)\right) \times \mathrm{V} / \mathrm{W} \times 1000$

Where,

$\mathrm{A}_{663}=$ Absorbance values at $663 \mathrm{~nm}$

$\mathrm{A}_{645}=$ Absorbance values at $645 \mathrm{~nm}$

$\mathrm{A}_{480}=$ Absorbance values at $480 \mathrm{~nm}$
$\mathrm{W}=$ Weight of the sample in $\mathrm{g}$

$\mathrm{V}=$ Volume of the solvent used $(\mathrm{ml})$

\section{Results and Discussion}

Under late grown condition grain filling period of both genotypes viz. DL 1266-1 and Arina 166 coincided with heat stress. During clear sunny days observations were recorded. Temperature increased with increasing in light intensity and maximum temperature $\left(>40{ }^{\circ} \mathrm{C}\right)$ was recorded during midday (Fig. 1).

\section{Diurnal variation in photosynthetic pigments}

Diurnal variations in photosynthetic pigments i.e. $\mathrm{Chl}_{\mathrm{a}}, \mathrm{Chl}_{\mathrm{b}}$, total chlorophylls and total cartenoids were noted throughout day in DL 1266-1 and Arina 166 and their maximum contents were noted during midday. However, higher alerations in the content $\mathrm{Chl}_{\mathrm{a}}, \mathrm{Chl}_{\mathrm{b}}$, total chlorophylls and total cartenoids of were noted in DL 1266-1(Fig. 2 A) than Arina 166 (Fig. 2 C). Since the concentration of all photosynthetic pigments was recorded on fresh weight basis and fresh weight is decreased in noon hours due to higher rate of transpiration from the leaves, therefore, on fresh weight basis higher content of photosynthetic pigment was obtained during midday. In other words, during midday pigment concentration was increased due to the increase in pigment density or reduction in tissue volume under high temperature. Suping and Abaraha (2007) also reported that extended exposure to $38^{\circ} \mathrm{C}$ led to water loss in turf grass cultivar, which resulted in the apparent increase in protein and chlorophyll content in the leaf tissues. Chlorophyll and carotenoids are synthesized and degraded (photo-oxidized) under irradiation. The antioxidative defense system is involved in the delayed senescence (stay green trait) in wheat (Hui et al., 2012). Thus, probably, due to better antioxidant activity and stronger 
photoprotective mechanism, higher levels of photosynthetic pigments during middday were obtained in wheat genotype DL 1266-1 as compared to Arina 166.

In both genotyps DL 1266-1 and Arina 166 ratio of $\mathrm{Chl}_{\mathrm{a}}$ : $\mathrm{Chl}_{\mathrm{b}}$ was also reported relatively higher during noon hours (Fig. 2 B \& D). Similarly, ratio of total cart: total chl peaked during midday in Arina. However, ratio of total cart: total chl in DL 1266-1 was estimated higher throughout from midday to evening hours which in turn indicated better protective role of carotenoids in DL 1266-1 under heat stress condition (Fig. 2 B \& D). Ratio of $\mathrm{Chl}_{\mathrm{a}}$ : $\mathrm{Chl}_{\mathrm{b}}$ and $\mathrm{T}$ Cart: $\mathrm{T}$ Chl were also found to be associated with heat tolerance in tomato (Camejo and Torres, 2001).

Fig.1 Diurnal variations in temperature and photosynthetically active radiation (PAR) during the data recording sunny days

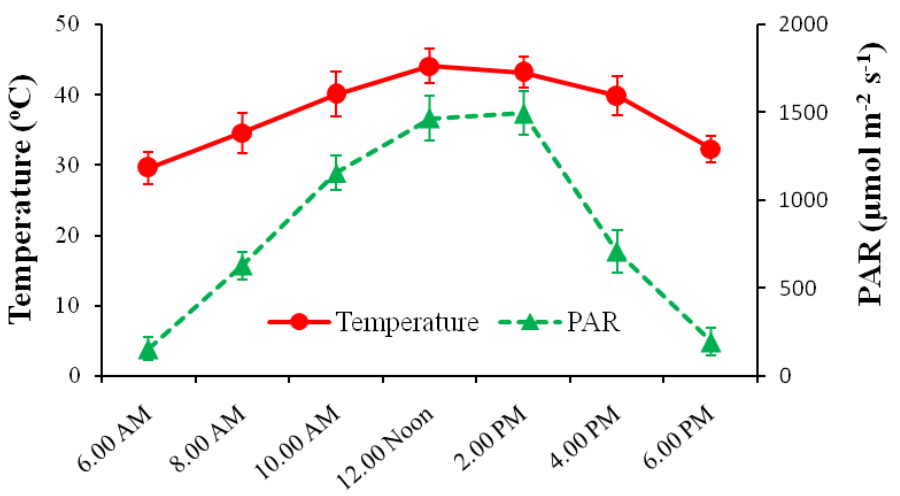

Fig.2 Diurnal variations in photosynthetic pigments [chlorophyll ' $a$ ' $\left(\mathrm{Chl}_{\mathrm{a}}\right)$, chlorophyll 'b' $\left(\mathrm{Chl}_{\mathrm{b}}\right)$, total chlorophyll (T chl), total carotenoids (T Cart)] and their ratio $\left(\mathrm{Chl}_{\mathrm{a}}\right.$ : $\mathrm{Ch}_{\mathrm{b}}$ and T Cart: T Chl ratio) under heat stress condition in wheat genotypes DL 1266-1 (A \& B) and Arina 166 $(C \& D)$
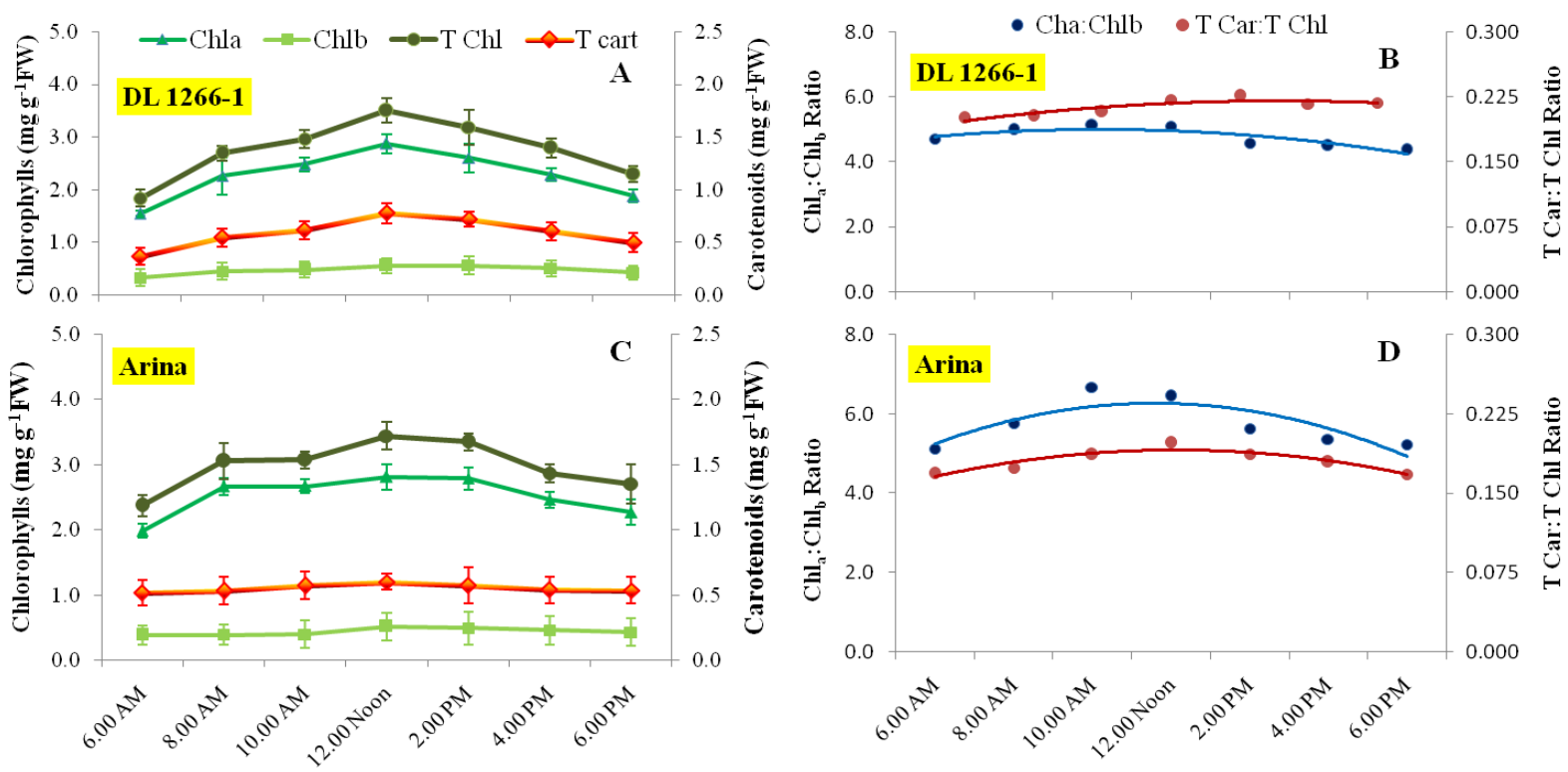
Fig.3 Diurnal variations in Chlorophyll flourescence parameters in wheat genotypes DL 1266-1

(A) and Arina 166 (B) under heat stress condition [Fo = Minimal fluorescence; Fv/Fm = Maximum photochemical efficiency of PS II; Fv'/Fm' = The efficiency of excitation capture by open PS II centers; qp = Photochemical quenching; NPQ = non-photochemical quenching]

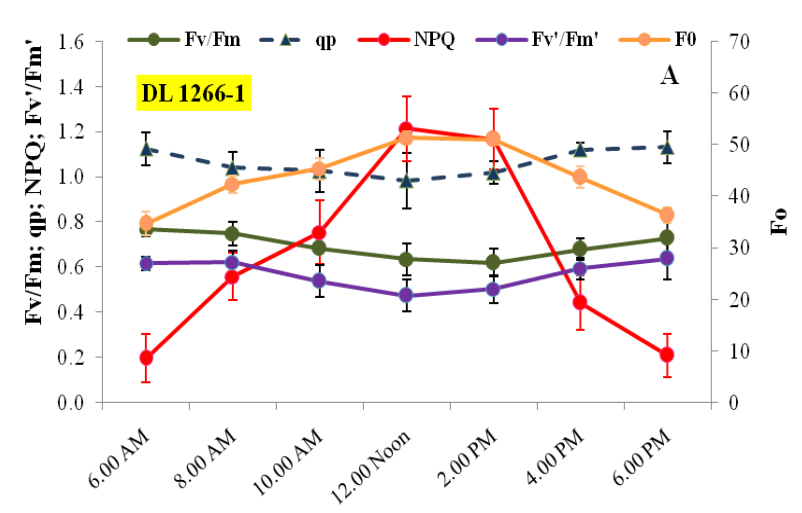

Diurnal variation in Chlorophyll flourescence parameters

During grain fillining period in both wheat genotypes viz DL 1266-1 and Arina 166 under heat stress condition chlorophyll fluorescence parameters alters throughout the day. Maximum alterations were noted during mid-day. Under high temperature condition in both genotypes viz DL 1266-1 and Arina 166, PSII efficiency (maximum quantum yield of PS II) $\left(F_{v} / F_{m}\right)$ was maximum early in the morning, afterwards it decreased up to midday and then it recovered in the late afternoon. Photosynthetic pigments (chlorophylls and carotenoids) and the minimal fluorescence $\left(\mathrm{F}_{\mathrm{o}}\right)$, on the contrary, were low in the early morning and highest during noon time (Fig. 3 A \& B).

Photoinhibition is marked by the decline of photosynthetic quantum efficiency and photochemical efficiency and Fv/Fm value is extensively used as an index to evaluate the extent of photoinhibition (Sayed 2003). In present study decrease in $\mathrm{Fv} / \mathrm{Fm}$ was found in noon (Fig. 3 A \& B) which indicates photoinhibition as well as damage to photosynthetic apparatus. It also decreases due to heat or other abiotic stresses (Panda 2011; Van

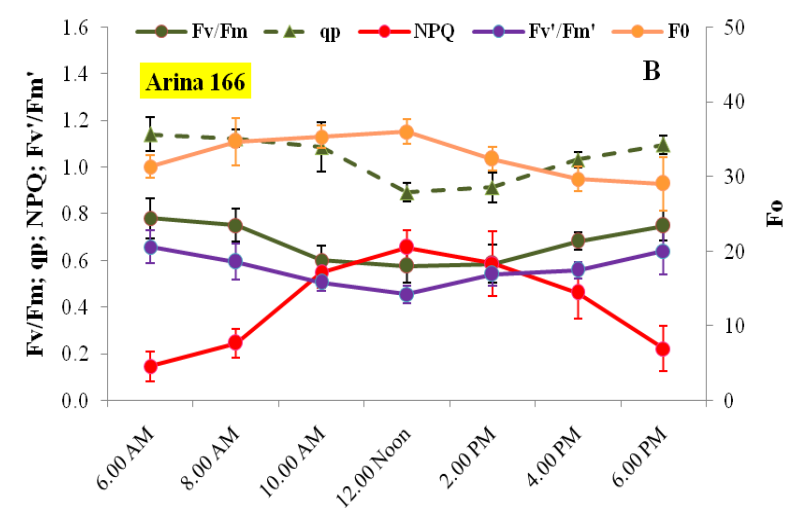

Goethem et al., 2013). But reversible alteration in $\mathrm{Fv} / \mathrm{Fm}$ was found during the day that in turn indicated photo-protection rather than photo-damage. The decrease in $\mathrm{Fv} / \mathrm{Fm}$ is likely due to the reversible down regulation of PS II rather than the photo-damage to PS II or loss of D1 protein (Demming-Adam and Adams, 1996; Panda 2011). The increase in Fo was recorded during midday (Fig. 3 A \& B) was probably caused by PS II inactivation (Demming- Adam and Adams, 1996). Increase in Fo fluorescence has been identified as one of the most direct signs of photoinhibition (Aro et al., 1993). The decline in the value of Fm exhibits a reduction in the ability of PS II to reduce the primary acceptor QA (Calatayud and Barreno, 2001). In this study, over the course of the sunny day, initial decrease and subsequent increases in both photochemical quenching (qP) and the efficiency of excitation capture by open PSII centers $\left(\mathrm{F}_{\mathrm{v}}{ }^{\prime} / \mathrm{F}_{\mathrm{m}}{ }^{\prime}\right)$ were observed. Photochemical quenching $(\mathrm{qP})$ reflects the proportion of photon energy absorbed by the PSII light-harvesting complex (Ding et al., 2006). Diurnal trends of $\mathrm{qP}$ were similar to that of $F_{v}{ }^{\prime} / F_{m}$ ' (Fig. 3 A \& B). It decreased from morning to noon and recovered during the afternoon. The decrease in $\mathrm{qP}$ indicated a decrease in the proportion of the closed PSII 
reaction centers or in the proportion of the reduced state of QA (Genty et al., 1989). In the present study, there was a effective decrease in Fv'/Fm' i.e., an increase in the proportion of closed PS II centers and a decrease in the efficiency of excitation capture by open PS II center during noon hours (Fig. 3 A \& B) indicating the xanthophylls cycle dependant energy dissipation operated coessentially (DemmingAdam and Adams, 1996).

A contrary trend was found in the changes of non-photochemical quenching (NPQ) that increased from morning to afternoon and decreased thereafter which suggested the role of xanthophyll pigments in photoprotection of photosynthetic machinery during midday hours. Induction of NPQ in plants partially takes place through the xanthophyll cycle, in which violaxanthin is de-epoxidized to antheraxanthin and then zeaxanthin, enabling excess light energy to be harmlessly dissipated as heat (Ruban 2016).

Further, NPQ value was reported higher during noon hours in DL 1266-1 as compared to Arina 166 which in turn suggested stronger photoprotective mechanism in DL 1266-1.

Thus, it may be concluded that photosynthetic pigments mediated photoprotective regulation is involved for stay green trait in wheat. Genotypic diurnal varations in photosynthetic pigments and chlorophyll fluorescence parameters particularly of total chlorophyll, $\mathrm{chl}_{\mathrm{a}}$, total carotenoids, ratio of $\mathrm{Chl}_{\mathrm{a}}: \mathrm{Chl}_{\mathrm{b}} \&$ total carotenoids: total chlorophyll and nonphotochemical quenching (NPQ) were noted relatively sharper in DL 1266-1 as compared to Arina 166. Higher NPQ values recoded in DL 1266-1 during midday indicated that zeaxanthin cycle pigments based photoprotective mechanism is stronger in DL 12661 to cope with the diurnal peak of heat stress as compared to Arina 166.

\section{Acknowledgements}

The work was supported by funding from ICAR-IARI, New Delhi in-house project (Grant No. CRSCIARISIL20144047279). Thanks are also due to the Head, Division of Plant Physiology for providing the necessary facilities during the course of the investigation.

\section{References}

Arnon, D.I. 1949.Copper enzymes in isolated chloroplasts: Polyphenoloxidase in Beta vulgaris. Plant Physiology. 24: 1-15.

Aro, E.M., Virgin, I., and Anderson, B. 1993. Photoinhibition of photosystem II. Inactivation, protein damage and turnover. Biochimica Biophysica Acta. 1143:113-134.

Aslam, M., Majid A., Hobbs, P.R., Hashmi, N.I., and Byerlee, D. 1989. Wheat in the rice-wheat cropping system of the Punjab: A synthesis of on-farm research results: CIMMYT. PARC. Islamabad (Pakistan).11(1): 58.

Asseng, S., Ewert, F., Martre, P., Rötter, R.P., Lobell, D.B., Cammarano, D., and Reynolds, M. P. 2015. Rising temperatures reduce global wheat production. Nature Climate Change. 5(2): 143-147.

Calatayud, A., and Barreno, E. 2001. Chlorophyll a fluorescence, antioxidant enzymes and lipid peroxidation in tomato in response to ozone and benomyl. Environmental Pollution. 115: 283- 289.

Camejo, D., and Torres, W. 2001. High temperature effect on tomato (Lycopersicon esculentum) pigment and protein content and cellular viability. Cultivos Tropicales. 22(3): 13-17.

Demmig-Adams, B., Adams, W.W., III, Barker, D.H., Logan, B.A., Bowling, D.R., and Verhoeven, A.S.1996. Using chlorophyll fluorescence to assess the fraction of absorbed light allocated to thermal dissipation of excess excitation. - Physiolgia Plantarum. 98: 253264.

Demmig-Adams, B., and Adams, W.W. 1992. Photoprotection and other responses of plants to high light stress. Annual Review of Plant Physiology and Plant Molecular Biology. 43: 
599-626.

Demming-Adam, B., and Adams, W.W., III,.1996. Photosynthesis: harvesting sunlight safely. Nature. 384, 557-560.

Ding, L., Wang, K.J., Jiang, G.M., Li Y.G., Jiang, C.D., Liu, M.Z., Niu, S.L., and Peng Y. 2006. Diurnal variation of gas exchange, chlorophyll fluorescence, and xanthophyll cycle components of maize hybrids released in different years Photosynthetica. 44 (1): 26-31.

Evans, L.T., Wardlaw, I.F. and Fischer, R.A. 1975. Wheat. In: L.T. Evans, ed. Crop Physiology, p. 101-149. Cambridge, UK, Cambridge University Press.

Genty, B., Briantais, J-M., and Baker, N.R. 1989. The relationship between the quantum yield of photosynthetic electron transport and quenching of chlorophyll fluorescence. Biochimica et Biophysica Acta. 990: 87-92.

Hendry, G.A.F., and Price A.H.1993. "Stress indicators: Chlorophylls and carotenoids". In: Methods in comparative plant ecology, Edited by: Hendry, GAF and Grime, J.P. 148-152. Chapman Hall, London.

Hiscocx, J. D. and Isralstam, G.F. 1997. A method for extraction of chlorophyll from leaf tissue without maceration Canadian Journal of Botany. 57: 1332-1334.

Hui, Z., Tian, F.X., and Wang, G.K. 2012. The antioxidative defense system is involved in the delayed senescence in a wheat mutant tasg1. Plant Cell Report. 31, 1073-1084.

Ivanov, A.G., Hurry, V., Sane, P.V., Цquist, G., and Huner, N.P.A. 2008. Reaction centre quenching of excess light energy and photoprotection of photosystem II. Journal of Plant Biology. 51: 85-96.

Lichtenthaler, H. K., and Wellburn, A.R. 1983. Determination of total carotenoids and chlorophyll a \& b of leaf extracts in different solvents. Biochemical Society Transactions. 11: 591-592.
Panda, D. 2011. Diurnal variations in gas exchange and chlorophyll fluorescence in rice leaves: the cause for midday depression in $\mathrm{CO}_{2}$ photosynthetic rate. Journal of Stress Physiology \& Biochemistry. 7 (4): 175-186.

Ruban, A.V. 2016. Non photochemical chlorophyll fluorescence quenching: mechanism and effectiveness in protecting plants from photodamage. Plant Physiology. 170(4): 1903-1916.

Sayed, O.H. 2003. Chlorophyll fluorescence as a tool in cereal crop research. Photosynthetica. 41: 321-330.

Schreiber, U., Bilger, W., and Neubauer, C. 1994. Chlorophyll fluorescence as a nonintrusive indicator for rapid assessment of in vivo photosynthesis. - In: Ecophysiology of Photosynthesis (ed.) Schulze, E.-D., Caldwell, M.M. Springer Verlag, Berlin. Pp. 49-70.

Suping, Z., and Abraraha, A. 2007. Response to heat stress in warm season and cool season turf grass cultivars. Scientific Research and Essay. 2: 95-100.

Thomas, H., and Howarth, C.J. 2000. Five ways to stay green. Journal of Experimental Botany. 51: 329-337.

Van Goethem D., De Smedt S., Valcke R., Potters G., and Samson R. 2013. Seasonal, Diurnal and Vertical Variation of Chlorophyll Fluorescence on Phyllostachys humilis in Ireland. PLoS ONE, 8(8), e72145. doi:10.1371/journal.pone.0072145

Zhang, X., Cai, J., Wollenweber, B., Liu, F., Dai, T., Cao, W., and Jiang, D. 2013. Multiple heat and drought events affect grain yield and accumulations of high molecular weight glutenin subunits and glutenin macropolymers in wheat. Journal of Cereal Science. 57: 134140.

\section{How to cite this article:}

Pramod Kumar. 2019. Diurnal Alterations in Photosynthetic Pigments and Chlorophyll Fluorescence in Stay Green Wheat (Triticum aestivum L.) Genotypes under Heat Stress. Int.J.Curr.Microbiol.App.Sci. 8(08): 2235-2241. doi: https://doi.org/10.20546/ijcmas.2019.808.259 